\title{
Video Article \\ Oscillation and Reaction Board Techniques for Estimating Inertial Properties of a Below-knee Prosthesis
}

\author{
Jeremy D. Smith ${ }^{1}$, Abbie E. Ferris ${ }^{1}$, Gary D. Heise ${ }^{1}$, Richard N. Hinrichs ${ }^{2}$, Philip E. Martin ${ }^{3}$ \\ ${ }^{1}$ School of Sport \& Exercise Science, University of Northern Colorado \\ ${ }^{2}$ Kinesiology Program, Arizona State University \\ ${ }^{3}$ Department of Kinesiology, lowa State University
}

Correspondence to: Jeremy D. Smith at jeremy.smith@unco.edu

URL: https://www.jove.com/video/50977

DOI: doi:10.3791/50977

Keywords: Bioengineering, Issue 87, prosthesis inertia, amputee locomotion, below-knee prosthesis, transtibial amputee

Date Published: 5/8/2014

Citation: Smith, J.D., Ferris, A.E., Heise, G.D., Hinrichs, R.N., Martin, P.E. Oscillation and Reaction Board Techniques for Estimating Inertial Properties of a Below-knee Prosthesis. J. Vis. Exp. (87), e50977, doi:10.3791/50977 (2014).

\section{Abstract}

The purpose of this study was two-fold: 1) demonstrate a technique that can be used to directly estimate the inertial properties of a below-knee prosthesis, and 2) contrast the effects of the proposed technique and that of using intact limb inertial properties on joint kinetic estimates during walking in unilateral, transtibial amputees. An oscillation and reaction board system was validated and shown to be reliable when measuring inertial properties of known geometrical solids. When direct measurements of inertial properties of the prosthesis were used in inverse dynamics modeling of the lower extremity compared with inertial estimates based on an intact shank and foot, joint kinetics at the hip and knee were significantly lower during the swing phase of walking. Differences in joint kinetics during stance, however, were smaller than those observed during swing. Therefore, researchers focusing on the swing phase of walking should consider the impact of prosthesis inertia property estimates on study outcomes. For stance, either one of the two inertial models investigated in our study would likely lead to similar outcomes with an inverse dynamics assessment.

\section{Video Link}

The video component of this article can be found at https://www.jove.com/video/50977/

\section{Introduction}

To quantify the resultant joint forces and moments during movement, an inverse dynamics model of the system of interest is needed when working with empirical data. For lower extremity biomechanics, inverse dynamics models typically represent the foot, shank, and thigh as rigid bodies. Input for these models come from three primary sources: a) motion kinematics, b) ground reaction forces, and c) segment anthropometrics and inertial properties. Motion data are collected with a variety of motion analysis systems, but all systems essentially provide the basic kinematics of the movement (position, velocity, and acceleration). Ground reaction forces are collected with a force plate and provide the contact forces acting on the feet. Anthropometrics are measurements taken directly from the body using rulers, flexible tapes, and/or calipers. These anthropometric measurements are used to estimate the inertial properties of the body segments used in the inverse dynamics analyses. Inertial properties include the mass, center of mass (COM) location and moment of inertia (MOI) of the segment relative to an axis through the segment COM or the proximal or distal joint. Methodologies and equipment used for collecting motion and ground reaction force data are similar among research groups, but inertial estimations of body segments can vary widely among researchers depending on which method the researcher chooses for estimating these inertial properties.

Various techniques available for estimating the inertial properties of a fully intact human body segment include: 1) regression equations based on cadaver data ${ }^{1-5}, 2$ ) mathematical models (i.e., geometric models) $)^{6,7}$, and 3) scanning \& imaging techniques ${ }^{8-15}$. Many of these techniques require direct measurements from the body, but it has previously been shown that regardless of the estimation method being used, the precision of body segment inertial estimates based on these methods is high ${ }^{16}$. It has also been shown that errors in the estimates of the inertial properties of intact body segments have minimal impact on the magnitudes of resultant joint moments during walking ${ }^{17,18}$. Joint moments are influenced to a greater extent by ground reaction forces, center of pressure locations, moment arm lengths, and segment kinematics ${ }^{17-19}$. Therefore, it is not surprising that methods for estimating inertial properties of body segments vary widely across the literature when using able-bodied individuals as research participants given that small errors in these estimates are likely to have little impact on outcomes of the study.

Many of these inertial estimations for a fully intact body segment are often used for estimating the inertial properties of prostheses for lower extremity amputees. Modern lower limb prostheses are fabricated using lightweight materials resulting in prosthetic limbs that are much lighter than the limbs they replace. This results in an inertial asymmetry between the prosthetic limb and intact limb. Compared with a typical intact shank and foot, the mass of a below-knee prosthesis and residual limb is approximately $35 \%$ less and has a center of mass located approximately $35 \%$ closer to the knee joint ${ }^{20-23}$. The lower mass and more proximal mass distribution of the prosthetic limb also produces a much lower $(\sim 60 \%)$ moment of inertia relative to the knee joint for the prosthetic limb compared to that of the intact shank and foot. Although researchers ${ }^{24,25}$ have previously suggested that using intact inertial estimates for the prosthetic limb have little effect on joint kinetic estimates, 
these comparisons focused on resultant joint moments during the stance phase of walking, where the ground reaction force dominates the moment produced at the joint. During swing, where ground reaction forces are not present, the reduced inertial properties of the prosthesis are more likely to influence estimates of resultant joint moments. Given that some researchers e.g., ${ }^{26-32}$ utilize intact segment inertia properties to represent prosthesis inertial properties and otherse.g. ${ }^{21-23}$ estimate prosthesis inertial properties directly, it is important to understand the impact of the methods chosen for estimating the inertial properties of the prosthesis. Minimizing the time required for measuring inertial properties of the prosthesis was an important consideration in the development of our technique. In the technique presented here the prosthesis remains fully intact for all measurements to reduce measurement times and avoid any additional times associated with realigning the prosthesis after measurement.

Thus, the purpose of this study was two-fold: 1) demonstrate a technique that can be used directly to estimate the inertial properties of a belowknee prosthesis, and 2) contrast the effects of the proposed technique and that of using intact limb inertial properties on joint kinetic estimates during walking in unilateral, transtibial amputees. It was hypothesized that joint kinetic magnitudes are larger when inertial properties of the intact shank and foot are used as the inertial estimates for the prosthesis compared to direct measurements of the prosthesis inertial properties.

\section{Protocol}

\section{Participants}

Six unilateral, transtibial amputees ( 5 males; 1 female; age $=46 \pm 16$ years, mass $=104.7 \pm 9.7 \mathrm{~kg}$, height $=1.75 \pm 0.08 \mathrm{~m}$ ) participated in this study. Five of six amputees had amputations due to traumatic injuries with the other due to congenital bone disease. All amputees used a lock and pin type suspension system for the prosthetic socket interface and a dynamic elastic response prosthetic foot (3 College Park, 2 Flex-foot, and 1 Genesis II). Participant recruitment focused on amputees who were fully ambulatory, had used a lower limb prosthesis for at least one year, and maintained some degree of physical activity either in their vocational or daily activities. The protocol was approved by the university's Institutional Review Board, and informed consent was obtained from each participant prior to participation.

\section{Overground Walking Trials}

Each participant's preferred walking speed was determined as the participant walked along a $20 \mathrm{~m}$ walkway using a comfortable speed as if walking from their car to the entrance of a store. A photocell-based timing system was used to quantify the time required to traverse approximately a $5 \mathrm{~m}$ section in the middle of the walkway. Preferred walking speed was quantified as the mean of five trials. Each participant then completed five successful overground walking trials while ground reaction forces from two force plates $(480 \mathrm{~Hz})$ and motion $(60 \mathrm{~Hz})$ data from a six-camera motion analysis system were collected. Successful trials were those within $\pm 3 \%$ of the participant's preferred speed and there was no visible indication of adjusting the stride to contact the force platform. Retroreflective markers were placed bilaterally on the greater trochanter, lateral femoral condyle, lateral malleolus, lateral aspect of the heel, and the head of the fifth metatarsal prior to data collection.

A three-segment (thigh, shank, and foot) sagittal plane inverse dynamics model was used to estimate resultant joint forces and moments at the hip, knee, and ankle. Segment inertial properties for intact body segments were estimated based on regression equations from de Leva ${ }^{8}$. Inertial properties of the prosthesis and residual limb were measured directly and distributed between the prosthetic shank and foot (see step by step protocol below). A single factor MANOVA with repeated measures was used to determine the effect of prosthesis inertia estimates, either direct measures or using estimates of the intact segment, on peak resultant joint forces and moments during stance and swing. Given that resultant joint reaction force and moment profiles were similar among all participants, an algorithm was written in MATLAB (Mathworks, Natick, MA) to focus on specific windows within the gait cycle to identify each of the individual peak quantities (See \% gait cycle in Table 2). A Bonferron adjustment to the confidence intervals was made based on the number of dependent variables. Significance differences were considered at $\mathrm{p}<$ 0.05 .

\section{Description of the Oscillation and Reaction Board Systems}

The Oscillation system used to measure the inertial properties of a prosthesis includes an outer cage or support structure made of $80 / 20$ aluminum, an inner aluminum cage that is adjustable, and an infrared photocell (see Figure 1A). The inner cage is suspended from the outer cage with an axle that passes through two low friction press-fit bearings. To accommodate different sized prostheses the inner cage can be shortened or lengthen by approximately $15 \mathrm{~cm}$ (or 6 inches). In addition, the inner cage also has two adjustable plates that are used to ensure a secure fit of the prosthesis within the cage. A plate with a set screw is used to ensure that oscillations of the inner cage have less than $5^{\circ}$ of amplitude so that estimations can be based on equations of simple harmonic motion. The photocell is wired directly to a counter on a data acquisition card in the computer to record each TTL pulse as the cage passes in front of the photocell. A LabView Virtual Instrument (VI) program is used to collect and process the TTL pulses. The inner cage of the oscillation system (Figure 1A) is used as the reaction board system (Figure 2) in combination with a scale with range up to $10 \mathrm{~kg}$ and sensitivity to the nearest $1 \mathrm{gram}$ and two knife edges used to support the inner cage during the reaction board measurements. The technique for quantifying the inertial properties of a below-knee prosthesis involves three main steps: 1) Oscillation and Reaction Board Protocol, 2) Mathematical Equations for Estimating Prosthesis Inertia, and 3) Distributing Prosthesis Inertia into Foot and Shank Segments. 

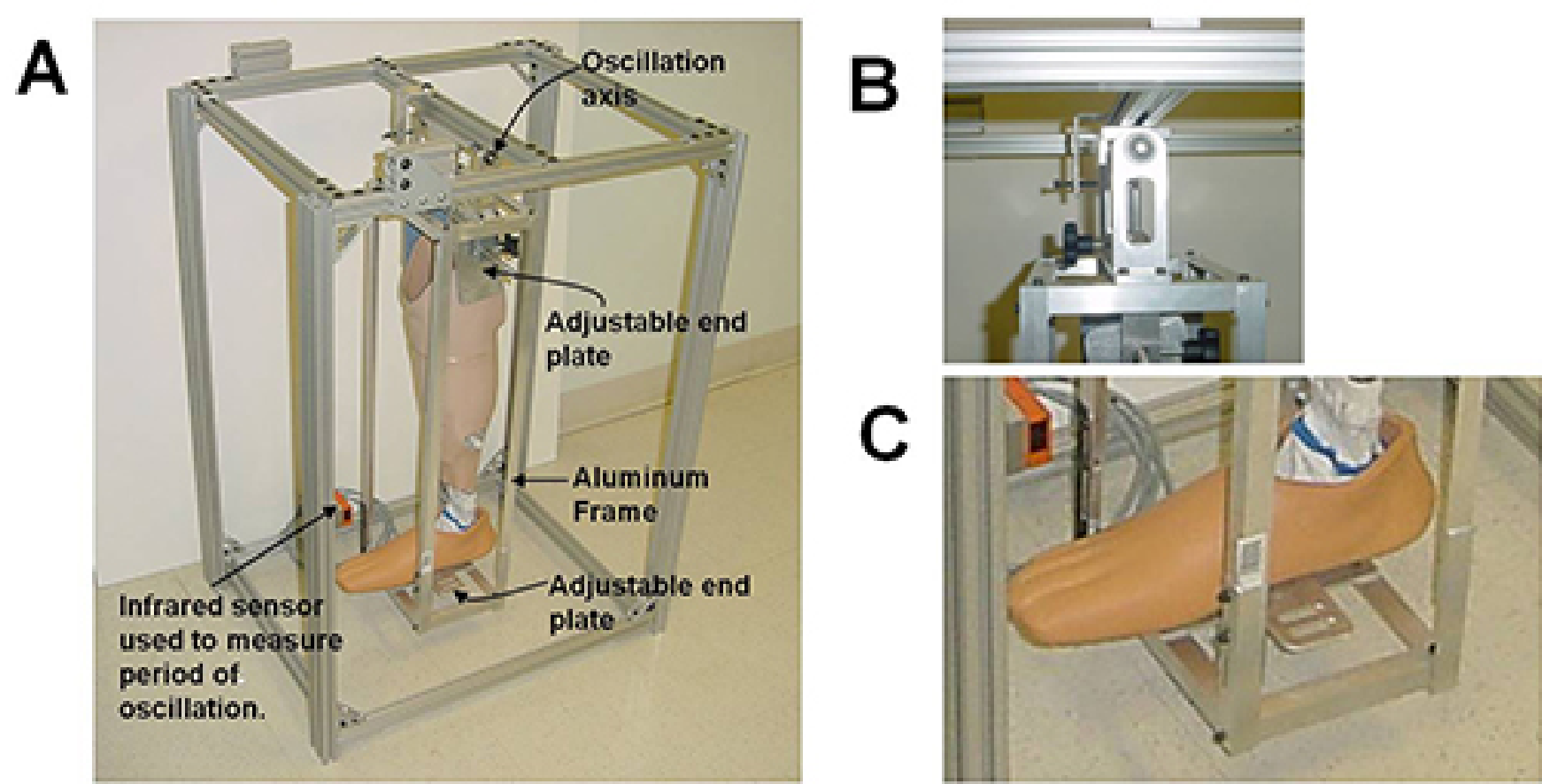

Figure 1. A) Image of the oscillation rack used for measuring the period of oscillation. Notice that there is an outer support structure that remains stationary as the inner cage, in which the prosthesis is fixed, oscillates back and forth in front of a photocell used for timing. B) Close-up view of the oscillation axis that also shows the set screw used to set oscillation amplitudes to less than $5^{\circ}$. C) Close-up view of the photocell and distal end of the inner cage to illustrate the adjustable end plates. Note that to reduce the weight of the inner cage we used thin aluminum and removed any excess aluminum without sacrificing the strength of the structure.

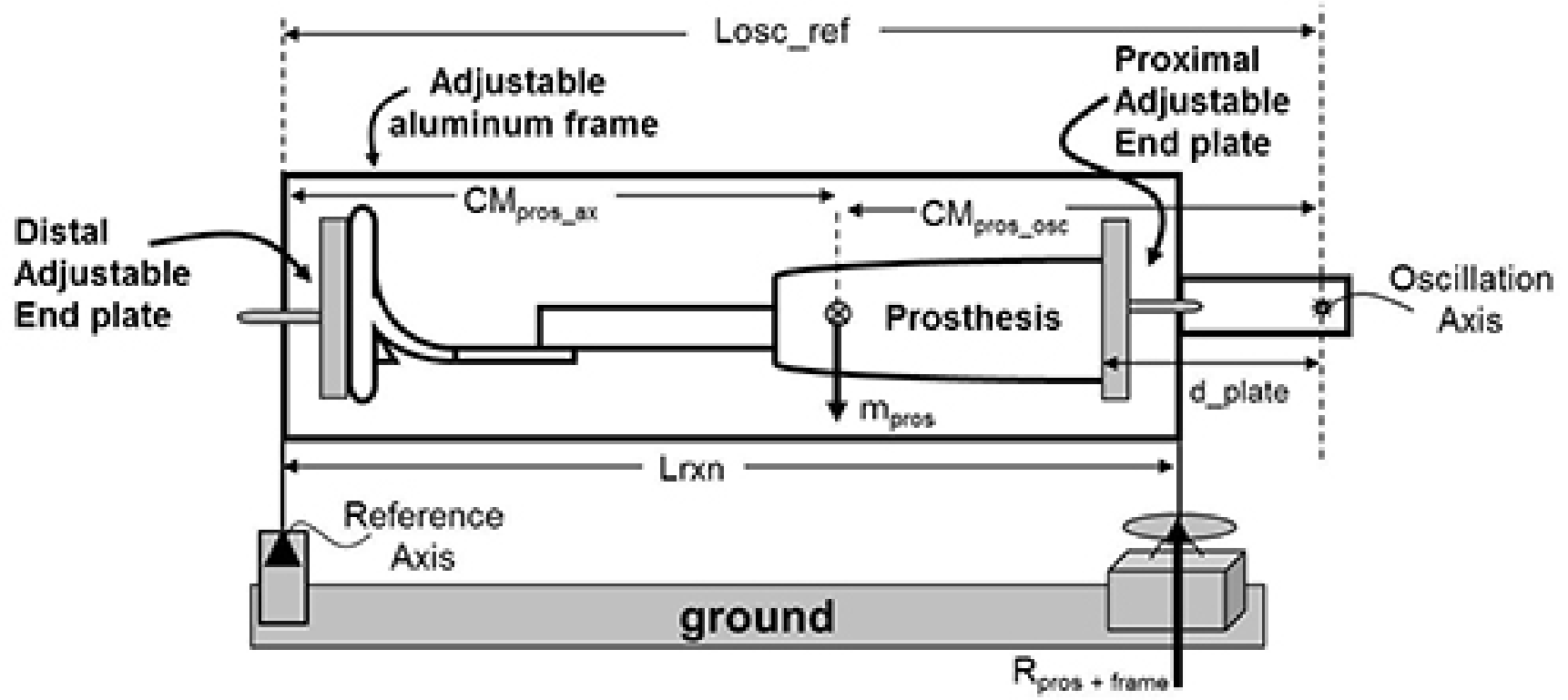

Figure 2. Reaction board schematic of the adjustable aluminum frame (i.e., inner cage) removed from the outer support structure of the oscillation system illustrating the reaction board setup used for estimating the system's center of mass. Note that two axes (a.k.a, knife edges) are used to support the inner cage; one at the left (distal) edge of the cage and the other (proximal) positioned over the top of the scale. The distance between these two supporting axes represents the length of the reaction board. The oscillation axis is coming out of the page.

\section{Inertial Measurement Protocol}

1. Initially, have the amputee sit in a chair where the prosthetic leg can be comfortably lifted off the seat so that the person can perform a series of knee flexion and extension actions as the knee center of rotation (COR) is identified.

2. Once the knee COR is identified (it may be helpful to place a small piece of tape at the COR), have the amputee stand and measure the following. 
1. Measure the distance from the top (lip) of the prosthesis to the knee COR; if the knee COR sits inferior to the lip of the prosthesis this value should be recorded as a negative value.

2. Measure the distance between the knee COR and the ankle COR. The ankle COR is assumed to be in a similar location as that of the intact ankle.

3. With the prosthesis and underlying sleeve removed, take several measurements of the residual limb using a flexible tape measure. Use these measurements to estimate the inertial properties of the residual limb based on modeling the residual limb as the frustum of a right circular cone ${ }^{6,21}$ and assuming a uniform tissue density of $1.1 \mathrm{~g} \cdot \mathrm{cm}^{-3} 13$

1. Measure the proximal circumference of the residual limb. This circumference should be measured as the largest circumference close to the knee joint (e.g., usually approximately two finger widths from the knee joint).

2. Measure the distal circumference of the residual limb. This circumference should be measured at the last bony prominence on the distal end of the residual limb.

3. Measure the length of the residual limb as the distance from the fibular head to most distal aspect of the residual limb.

4. Remove the inner cage from the oscillation rack by removing the axle. Put the amputee's liner and any ply the amputee is currently using within the socket of the prosthesis. Then securely position the prosthesis with shoe still on within the inner oscillation cage (Figure 1). In this system, two adjustable plates slide horizontally and when tightened into position secure the top of the prosthesis within the cage. For the foot of the prosthesis use a Velcro strap to secure it on distal plate of the cage.

5. Reposition the inner cage within the oscillation rack. Secure the axle and make sure the suspending arm of the inner cage aligns with the set screw that will set the angle of oscillation to less than $5^{\circ}$.

6. Collect three oscillation trials with the prosthesis positioned in the inner cage. The period of oscillation will represent the time it takes to complete one full oscillation with the inner cage swinging under its own weight and influenced only by gravity. To begin an oscillation trial pull the inner cage back until it hits the set screw and then move it forward until space between the set screw and inner cage is visible. Record the average time for one complete cycle of oscillation for each trial.

7. Prior to shifting to the reaction board measurements, measure and record the following dimensions of the inner cage with the prosthesis still fixed in the rack using digital calipers or a flexible measuring tape. These measures will be used if the inner cage configuration changes upon removing the prosthesis in Step 1.9 and also during estimations of the inertial properties of the system. These measurements are easier to take with the inner cage positioned horizontally and resting on the knife edges for the reaction board test.

1. Measure the distance between the top adjustable plate and the fixed cross-member at the top of the inner cage.

2. Measure the distance between the bottom adjustable plate and the fixed cross-member at the top of the inner cage.

3. Measure the distance between the bottom adjustable plate and the fixed cross-member at the bottom of the inner cage.

4. Measure the length of the reaction board; this is the distance between the locations of the two knife edges that will be used as supports during the reaction board test.

8. Position the rack and prosthetic limb in the reaction board setup. Make sure the scale reads zero at this point. Place one end of the inner cage over the scale, and position the knife edge at the bottom of the inner cage so that there is no tension created between the two knife edges and the inner cage is level. Lift the scale-end several times and place it back down on the scale. Once a consistent reading from the scale is achieved, record this value.

9. Remove the prosthesis from the inner cage. If the top and/or bottom plates had to be moved to remove the prosthesis, return the plates to their original position using the dimensions measured in Step 1.7. Once cage dimensions are what they were with the prosthesis in the cage, repeat Step 1.8 to record the reaction board reading for just the cage.

10. Remove the shoe from the prosthetic limb and measure the mass of the shoe, followed by the mass of the prosthesis without the shoe.

11. Take several measurements of the prosthesis.

1. Measure the distance between COR of ankle and the plantar surface of the foot.

2. Measure the length of prosthetic foot without the shoe.

3. Place the shoe back on the prosthesis and measure the distance from the ankle COR to sole of shoe and the length of the foot with the shoe on.

12. Reposition the inner cage within the oscillation rack making sure that the black corner with reflective tape is closest to the photocell. Secure the axis and make sure the suspending arm of the inner cage aligns with the set screw that will set the angle of oscillation to less than $5^{\circ}$. Collect 10 oscillation trials, where this time only the first oscillation period of each trial will be recorded. Note: See Appendix A for explanation about why we use only the first oscillation period when the inner cage is oscillated by itself without the prosthesis.

\section{Mathematical Equations for Estimating Prosthesis Inertia}

1. Adjust body mass to account for the reduced mass of the prosthetic prior to estimating intact segment inertial properties using the following equation:

$\mathrm{ABM}=\frac{\mathrm{MBM}-\mathrm{M}_{\text {pros }}-\mathrm{M}_{\text {residual }}}{1-\mathrm{c}}$ (1)

where $A B M$ is the adjusted body mass, MBM is the measured body mass while wearing the prosthesis, $M_{\text {pros }}$ is the mass of the prosthesis, $M_{\text {residual }}$ is the mass of the residual limb (anatomical structures below the knee that remain after amputation), and $c(0.057$ for males; 0.061 for females) is percent of ABM accounted for by the intact shank and foot ${ }^{8}$.

2. Estimate the inertial properties of the thigh, shank and foot of the intact leg and thigh of the prosthetic leg based on the ABM and their respective segment lengths ${ }^{8}$.

3. The prosthesis center of mass location is first expressed relative to the reference axis (Figure 2):

$\mathrm{CM}_{\text {pros_ax }}=\left(\operatorname{Lrxn}{ }^{*}\left(\mathrm{R}_{\text {pros }+ \text { frame }}-\mathrm{R}_{\text {frame }}\right)\right) / \mathrm{m}_{\text {pros }}(2)$

where $\operatorname{Lrxn}$ represents the distance between points of support, $R_{\text {prostframe }}$ represents the scale reading for the prosthesis and aluminum frame together, $R_{\text {frame }}$ represents the scale reading for the frame only, and $m_{\text {pros }}$ represents the mass of the prosthesis. 
4. Based on the distance between oscillation and reference axes (Losc_ref) the center of mass location of the prosthesis is expressed relative to the oscillation axis:

$\mathrm{CM}_{\text {pros_osc }}=$ Losc_ref $-\mathrm{CM}_{\text {pros_ax }}(3)$

This is needed in subsequent computations of the moment of inertia of the prosthesis relative to this oscillation axis.

5. Finally, the center of mass location is expressed relative to the proximal end of the prosthetic socket based on the distance between the oscillation axis and the top adjustable end plate (d_plate):

$\mathrm{CM}_{\text {pros_prox }}=\mathrm{CM}_{\text {pros_osc }}-\mathrm{d} \_$plate $(4)$

6. Compute the moment of inertia for each condition (cage alone and cage + prosthesis):

$\mathrm{I}_{\mathrm{axis}}=\left(\frac{\tau}{2 \pi}\right)^{2} \operatorname{mgd}(5)$

where $I_{\text {axis }}$ is the moment of inertia relative to the oscillation axis, $\mathrm{T}$ is the average period of one oscillation, $\mathrm{m}$ is the mass of the system, $\mathrm{g}$ is the acceleration due to gravity, and $d$ is the distance between the oscillation axis and the center of mass of the system. The moment of inertia of the prosthesis relative to the oscillation axis is computed as the difference between $I_{\text {axis }}$ for the cage alone and $I_{\text {axis }}$ for the cage plus prosthesis. The parallel axis theorem is then used to express the moment of inertia of the prosthesis about a transverse axis through knee joint.

7. Combine the inertial properties of the residual limb and prosthesis to determine the combined mass, center of mass position relative to the knee, and using the parallel axis theorem express the moment of inertia of the system about a transverse axis through the combined center of mass location.

\section{Distributing Prosthesis Inertia into Foot and Shank Segments}

To distribute the inertial properties of the prosthesis and residual limb into a foot (prosthetic foot only) and shank segment (prosthetic socket, pylon, and residual limb) for inverse dynamics modeling segment inertial properties were determined based on data from a dismantled prosthesis. The total mass of the dismantled prosthetic limb was $2.126 \mathrm{~kg}$, with a socket mass (including pylon mass) of $1.406 \mathrm{~kg}$ and a foot mass of $0.72 \mathrm{~kg}$. Thus, $66 \%$ of total prosthesis mass was apportioned to the prosthetic socket and $34 \%$ was apportioned to the foot. A sensitivity analysis was performed to determine what effect this had on the estimated moment of inertia of the prosthesis about the knee joint. This analysis was based on experimental measurements of the inertial properties of six below knee prostheses from Mattes et al. ${ }^{21}$ (data were obtained via personal communication with the authors). When the prosthetic shank and foot masses were determined based on de Leva ${ }^{8}$ (foot $=24 \%$; shank $=76 \%$ of total prosthesis mass), the total moment of inertia of the prosthesis about the knee joint was underestimated by approximately $5 \%$ compared to the actual experimental value estimated using an oscillation technique. Using percentages based on the dismantled prosthesis for foot $(34 \%)$ and shank $(66 \%)$ masses, the total moment of inertia about the knee joint was overestimated by approximately $2 \%$ compared to the experimental measure.

1. Distribute prosthesis mass between prosthetic foot (34\%) and socket $(66 \%)$ segments based on measurements of a dismantled prosthetic limb.

2. COM location of the prosthetic foot was determined based on regression equations for an intact foot ${ }^{8}$. This step was based on the results of sensitivity analyses from Miller ${ }^{25}$ and Czerniecki et $\mathrm{al}^{24}$. Miller ${ }^{25}$ estimated resultant joint moments at the knee using: a) direct measurements of the prosthesis inertial properties, and b) using prosthesis inertial properties estimated from regressions equations for an intact shank and foot. The average difference between knee moment profiles for the two different methods and for two subjects was approximately $3 \mathrm{~N} \cdot \mathrm{m}$. This average difference in magnitude amounted to less than $2 \%$ of the peak knee moment during stance. Czerniecki et al. ${ }^{24}$ dismantled multiple below-knee prostheses and balanced the prosthetic foot on a knife edge to determine its COM location. When they compared these results to estimates based on regression equations for an intact foot, they found that there was little difference between the two estimates.

3. $\mathrm{MOI}$ of the prosthetic foot about a transverse axis though its COM is determined using de Leva's ${ }^{8}$ regressions for an intact foot and the estimated foot mass from Step 1. MOI of the foot is also expressed relative to the knee joint using the parallel axis theorem.

Icm_FT $=$ mpros_ft $*(.245 * \text { Lfoot })^{2}(6)$

Iknee_FT $=\mathrm{Icm} \_\mathrm{FT}+\left(\operatorname{mpros\_ ft} * \mathrm{CMpros \_ ft}{ }^{2}\right)(7)$

4. COM location of the prosthetic socket (CMpros_sock) was determined by combining an estimate of the COM position for the entire prosthesis (CMpros_limb; not including the residual limb inertial properties), obtained with a reaction board technique, and the assigned COM location of the prosthetic foot relative to the knee joint (CMpros_ft) from Step 3.2. The CMpros_sock was constrained to lie on a straight line between the knee and ankle and was determined as:

CMpros_sock $=\frac{(\text { CMpros_li mb * mpros })-(\text { CMpros_ft } * \text { mpros_ft })}{\text { mpros_sock }}$

5. $\mathrm{MOI}$ of the prosthetic foot about an axis though the knee joint was subtracted from the experimental measurement for MOI of the entire prosthetic limb about the knee joint (Iknee limb) to determine MOI of only the prosthetic socket about the knee joint (Iknee sock). The parallel axis theorem was then applied to express $\mathrm{MOI}$ of the prosthetic socket about an axis through its COM (Icm_sock).

Iknee_sock $=$ Iknee_limb - Iknee_FT (9)

Icm_sock $=$ Iknee_sock $-($ mpros_sock $*$ CMpros_sock 2 )

6. The inertial properties of the residual limb (anatomical structures remaining below the knee after amputation) were combined with the inertial properties of the prosthesis shank, which were used as the inertial properties of the shank segment on the prosthetic side in the inverse dynamics model.

mpros_shan $\mathrm{k}=$ mpros_sock + mresidual 


$$
\begin{aligned}
& \text { CMpros_shank }=\frac{(\text { CMpros_sock } * \text { mpros_sock })+(\text { CMres * mresidual })}{\text { mpros_shan } k} \\
& \text { Iknee_shan } \mathrm{k}=\text { Iknee_sock }+ \text { Iknee_resi dual }(13) \\
& \text { Icm_shank }=\text { Iknee_shan } \mathrm{k}-\left(\text { mpros_shank }{ }^{*} \text { CMpros_shank }{ }^{2}\right)
\end{aligned}
$$

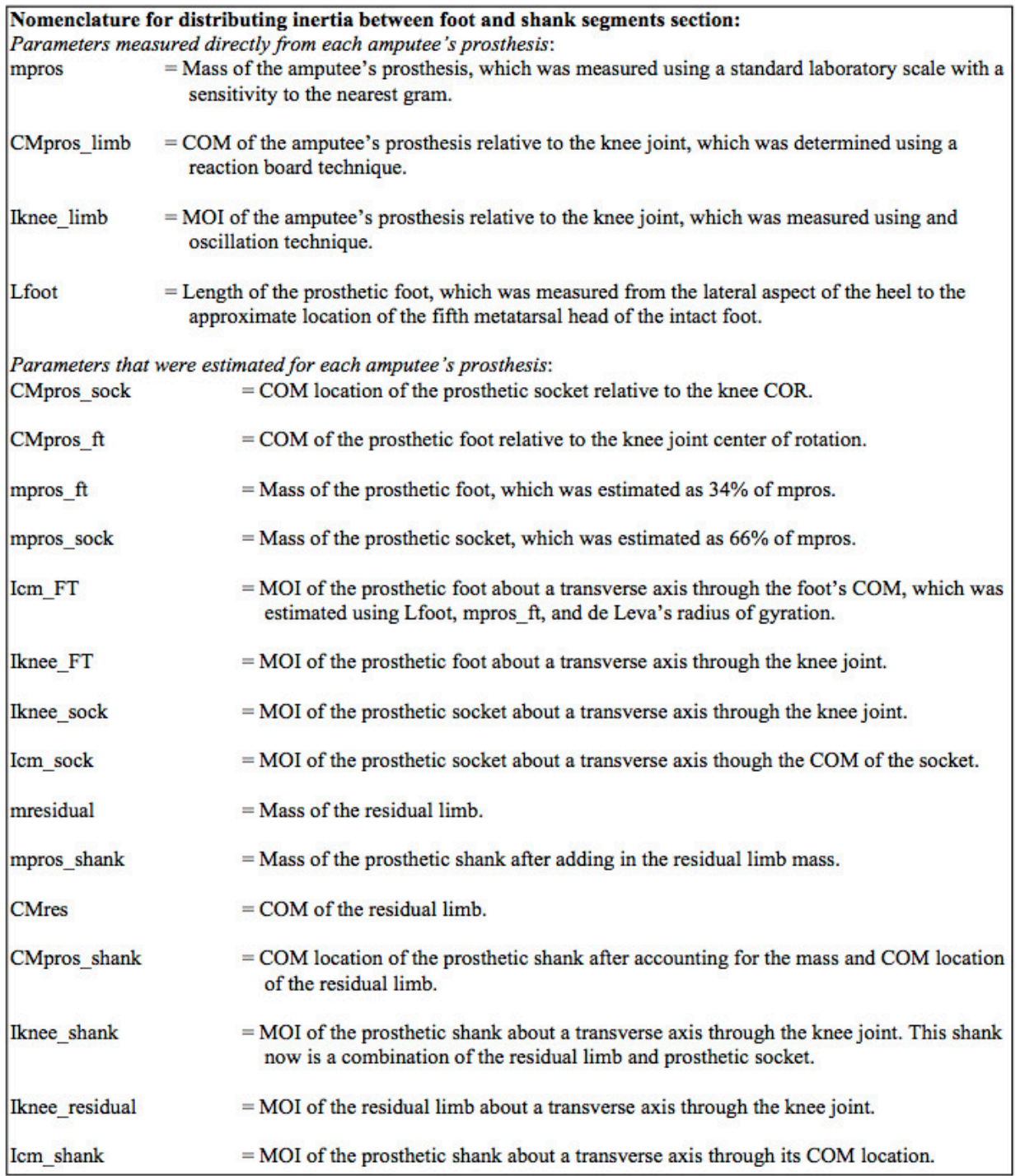

\section{Representative Results}

Inertial properties of the prosthetic leg distal to the knee were lower than those of the intact leg (Table 1). Averaged across participants, prosthetic side mass was $39 \%$ less, moment of inertia about a transverse axis through the knee was $52 \%$ less, and the center of mass location was $24 \%$ closer to the knee compared with values for the intact leg. 


\begin{tabular}{|c|c|c|c|c|c|c|c|}
\hline Subject & Intact ${ }^{*}$ Mass $(\mathrm{kg})$ & Pros $^{\dagger}$ Mass $(\mathrm{kg})$ & \begin{tabular}{|l|} 
Est. Mass \\
difference $(\mathrm{kg})$
\end{tabular} & $\begin{array}{l}{ }^{\ddagger} \mathrm{I} / \mathrm{kne} \\
\left(\mathrm{kg} \cdot \mathrm{m}^{2}{ }^{2}\right)\end{array}$ & lknee ${ }_{\text {pros }}\left(\mathrm{kg} \cdot \mathrm{m}^{2}\right)$ & $\begin{array}{l}\text { Intact CM below } \\
\text { the knee joint } \\
(\mathrm{m})\end{array}$ & $\begin{array}{l}\text { Pros CM below } \\
\text { the knee joint } \\
(\mathrm{m})\end{array}$ \\
\hline A & 6.03 & 4.27 & 1.76 & 0.604 & 0.325 & 0.268 & 0.215 \\
\hline$B$ & 6.07 & 3.39 & 2.68 & 0.400 & 0.196 & 0.215 & 0.177 \\
\hline C & 5.80 & 3.12 & 2.68 & 0.575 & 0.194 & 0.264 & 0.198 \\
\hline $\mathrm{D}$ & 5.72 & 3.17 & 2.55 & 0.559 & 0.317 & 0.265 & 0.191 \\
\hline $\bar{E}$ & 7.14 & 4.65 & 2.49 & 0.742 & 0.325 & 0.276 & 0.200 \\
\hline $\mathrm{F}$ & 6.23 & 4.22 & 2.01 & 0.585 & 0.287 & 0.260 & 0.192 \\
\hline Mean \pm STD & $6.17 \pm 0.51$ & $3.80 \pm 0.66$ & $2.36 \pm 0.38$ & $0.578 \pm 0.109$ & $0.274 \pm 0.063$ & $0.258 \pm 0.022$ & $0.196 \pm 0.013$ \\
\hline
\end{tabular}

"Intact refers to values for the combined intact shank and foot.

${ }^{\dagger}$ Pros refers to values for the combined prosthesis and residual limb.

${ }^{\ddagger}$ Moment of inertia about a transverse axis through the knee.

Table 1. Comparison of inertial properties between the prosthetic and intact limbs from the knee down.

Resultant joint forces (Figure 3) and moments (Figure 4) at the ankle, knee, and hip were affected by the inertial parameters used in the inverse dynamics model. Specifically, joint kinetics were reduced during swing initiation ( $65 \%$ of the gait cycle) and swing termination ( 95\% of the gait cycle) when direct measures of prosthesis inertia were used in inverse dynamics assessments compared with regressions based on intact anatomy (Table 2). Effect sizes suggest these differences during swing were not trivial ( $\geq 1.0)$. In addition, joint kinetic values increased on average by $80 \%$ during swing initiation and termination when intact inertial estimates were used compared with direct measures of the prosthesis inertial properties. Thus, when inertial properties of an intact limb were used to model the prosthetic side, joint kinetic profiles of the prosthetic side during swing more closely resembled those of an intact limb (see Figures $\mathbf{3}$ and $\mathbf{4}$ ). During stance, a number of statistical differences were observed. The largest effect size for any difference during stance was observed for the hip anterioposterior resultant joint force $(E S=$ $0.86)$. Although this effect size is large and still considered as part of stance, the peak value for this measure occurred during terminal stance $(\sim 52 \%)$, or as the limb was transitioning into swing. Effect sizes for all other significant differences observed during stance ranged from 0.01 to 0.41 , which would be considered small effects with the larger of these values being observed in the hip resultant joint reaction forces. Although significant differences were found during stance, these differences when considered in terms of the size of the difference (i.e., effect sizes) might lead one to question the meaningfulness of these differences.

Joint Reaction Forces
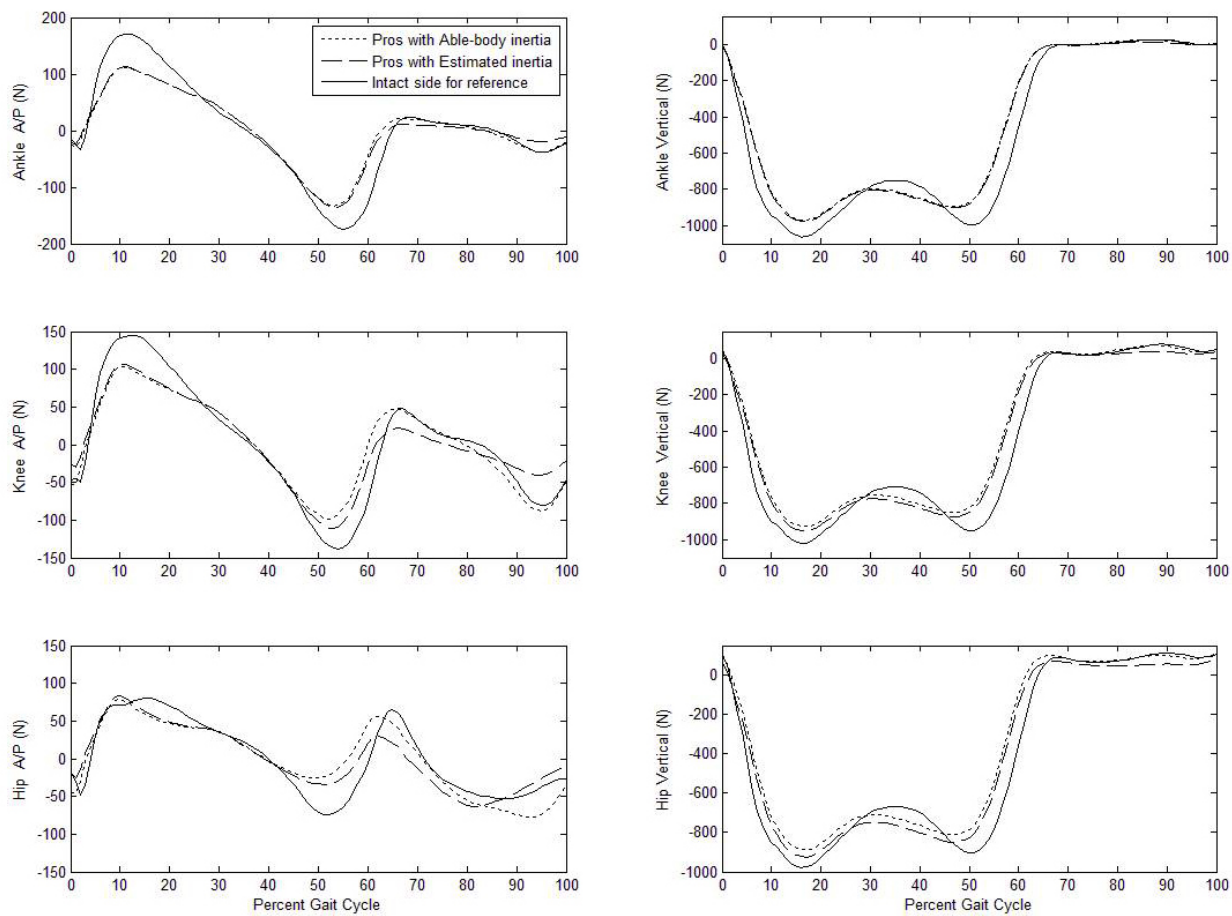

Figure 3. Resultant joint reaction forces of the ankle, knee, and hip in the anterioposterior (left panels) and vertical directions (right panels). Data were averaged across subjects for presentation. The stance phase begins at $0 \%$ of the gait cycle with foot contact and ends at approximately $60 \%$ of the gait cycle with toe-off. Swing continues until the next foot contact of the same leg at $100 \%$ of the gait cycle. Please click here to view a larger version of this figure. 

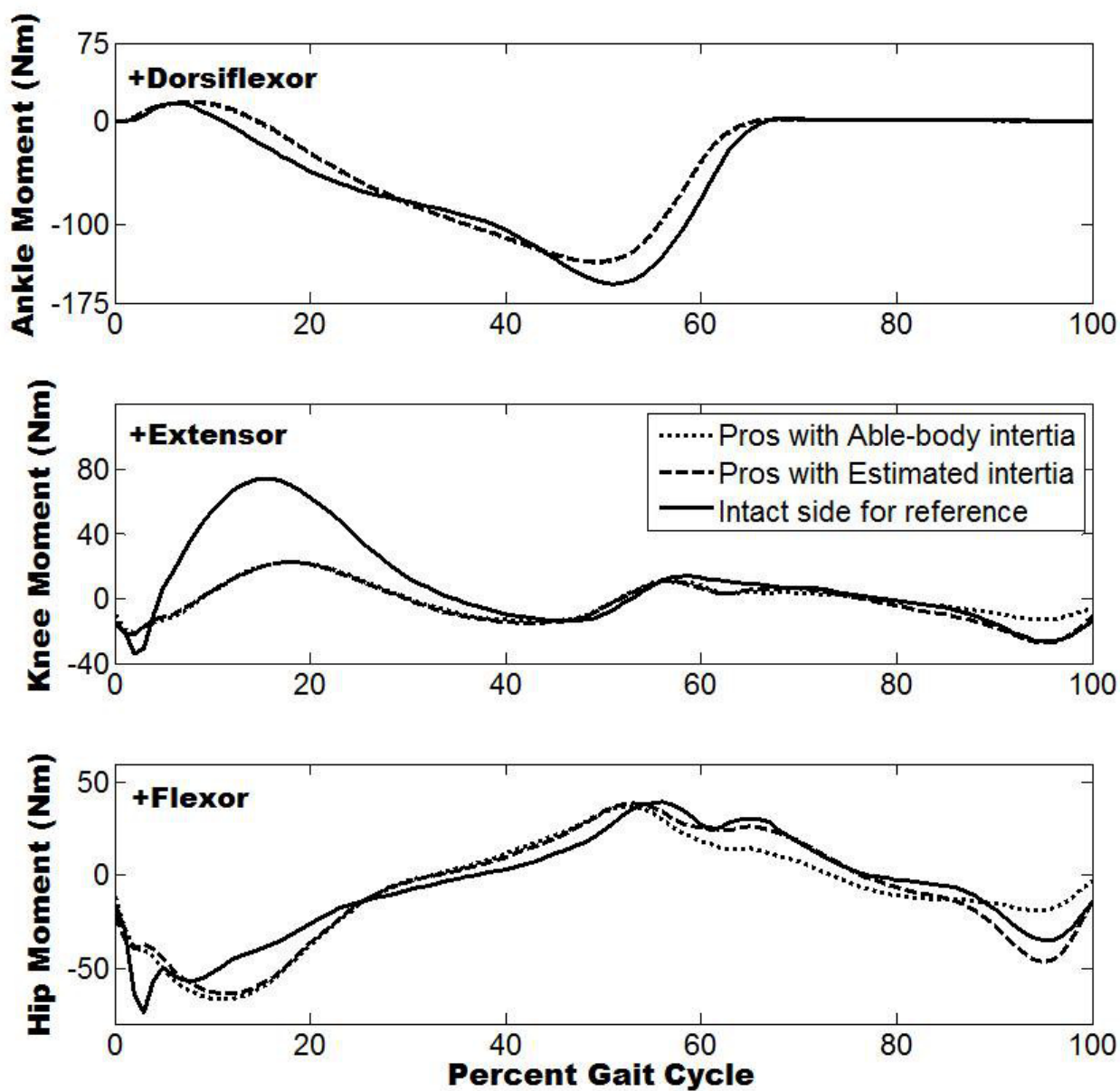

Figure 4. Resultant joint moments about a transverse axis (a.k.a, mediolateral axis) through the ankle, knee, and hip. Data were averaged across subjects for presentation. The stance phase begins at $0 \%$ of the gait cycle with foot contact and ends at approximately $60 \%$ of the gait cycle with toe-off. Swing continues until the next foot contact of the same leg at $100 \%$ of the gait cycle. 


\begin{tabular}{|c|c|c|c|c|c|c|}
\hline \multirow[b]{2}{*}{ Variable } & \multirow[b]{2}{*}{$\begin{array}{l}\% \text { Gait } \\
\text { Cycle }\end{array}$} & \multicolumn{2}{|c|}{ Inertial Model } & \multirow[b]{2}{*}{$\begin{array}{c}\text { Percent } \\
\text { difference }\end{array}$} & \multirow[b]{2}{*}{$p$ value } & \multirow[b]{2}{*}{$\begin{array}{c}\text { Cohen's d } \\
\text { (ES) }\end{array}$} \\
\hline & & $\begin{array}{c}\text { Direct } \\
\text { Measures } \\
\end{array}$ & $\begin{array}{c}\text { Intact } \\
\text { Estimates }\end{array}$ & & & \\
\hline \multicolumn{7}{|c|}{ Resultant Joint Forces (N) } \\
\hline $\begin{array}{c}\text { Ankle Anterioposterior } \\
\text { Early Stance } \\
\text { Terminal Stance }\end{array}$ & $\begin{array}{l}14 \% \\
55 \%\end{array}$ & $\begin{array}{c}135.0(24.4) \\
-150.1(17.2)\end{array}$ & $\begin{array}{c}134.2(24.3) \\
-147.0(16.2)\end{array}$ & $\begin{array}{l}0.6 \\
2.1\end{array}$ & $\begin{array}{l}0.004 \\
0.001\end{array}$ & $\begin{array}{l}0.03 \\
0.18\end{array}$ \\
\hline $\begin{array}{l}\text { Initial Swing } \\
\text { Terminal Swing } \\
\text { Ankle Vertical }\end{array}$ & $\begin{array}{l}66 \% \\
96 \%\end{array}$ & $\begin{array}{c}15.6(3.6) \\
-21.5(4.4)\end{array}$ & $\begin{array}{r}28.7(4.0) \\
-41.5(5.3)\end{array}$ & $\begin{array}{l}84.5 \\
92.8\end{array}$ & $\begin{array}{l}<0.001 \\
<0.001\end{array}$ & $\begin{array}{l}3.47 \\
4.13\end{array}$ \\
\hline $\begin{array}{r}\text { Early Stance } \\
\text { Mid-Stance } \\
\text { Terminal Stance }\end{array}$ & $\begin{array}{l}18 \% \\
32 \% \\
47 \%\end{array}$ & $\begin{array}{c}-1100.2(122.3) \\
-841.1(99.6) \\
-987.6(115.5)\end{array}$ & $\begin{array}{c}-1092.5(121.2) \\
-834.1(98.9) \\
-980.1(114.9)\end{array}$ & $\begin{array}{l}0.7 \\
0.8 \\
0.8\end{array}$ & $\begin{array}{l}<0.001 \\
<0.001 \\
<0.001\end{array}$ & $\begin{array}{l}0.06 \\
0.07 \\
0.07\end{array}$ \\
\hline $\begin{array}{c}\text { Initial Swing } \\
\text { Terminal Swing } \\
\text { Knee Anterioposterior }\end{array}$ & $\begin{array}{l}65 \% \\
98 \%\end{array}$ & $\begin{array}{l}5.1(2.1) \\
-1.1(1.4)\end{array}$ & $\begin{array}{l}8.8(4.0) \\
-2.1(2.4)\end{array}$ & $\begin{array}{l}70.4 \\
87.8\end{array}$ & $\begin{array}{l}0.008 \\
0.081\end{array}$ & $\begin{array}{l}1.14 \\
0.50\end{array}$ \\
\hline $\begin{array}{r}\text { Early Stance } \\
\text { Terminal Stance }\end{array}$ & $\begin{array}{l}14 \% \\
54 \%\end{array}$ & $\begin{array}{c}128.3(25 .) \\
-122.1(12.2)\end{array}$ & $\begin{array}{l}124.7(24.2) \\
-108.1(9.6)\end{array}$ & $\begin{array}{c}2.8 \\
11.4\end{array}$ & $\begin{array}{l}0.014 \\
0.001\end{array}$ & $\begin{array}{l}0.15 \\
1.28\end{array}$ \\
\hline $\begin{array}{l}\text { Initial Swing } \\
\text { Terminal Swing } \\
\text { Knee Vertical }\end{array}$ & $\begin{array}{l}65 \% \\
96 \%\end{array}$ & $\begin{array}{l}31.8(11 .) \\
-43.2(7.6)\end{array}$ & $\begin{array}{l}62.4(14.7) \\
-96.1(14.7)\end{array}$ & $\begin{array}{c}96.6 \\
122.3\end{array}$ & $\begin{array}{l}<0.001 \\
<0.001\end{array}$ & $\begin{array}{l}2.36 \\
4.52\end{array}$ \\
\hline Early Stance & $18 \%$ & $-1070.6(119.8)$ & $-1046.3(119.5)$ & 2.3 & $<0.001$ & 0.20 \\
\hline $\begin{array}{r}\text { Mid-Stance } \\
\text { Terminal Stance }\end{array}$ & $\begin{array}{l}32 \% \\
47 \%\end{array}$ & $\begin{array}{l}-811.9(97.1) \\
-958.8(112.2)\end{array}$ & $\begin{array}{l}-788.4(97.0) \\
-933.2(112.1)\end{array}$ & $\begin{array}{l}2.9 \\
2.7\end{array}$ & $\begin{array}{l}<0.001 \\
<0.001\end{array}$ & $\begin{array}{l}0.24 \\
0.22\end{array}$ \\
\hline $\begin{array}{r}\text { Initial Swing } \\
\text { Terminal Swing }\end{array}$ & $\begin{array}{l}65 \% \\
97 \%\end{array}$ & $\begin{array}{l}48.1(14.7) \\
25.6(7.3)\end{array}$ & $\begin{array}{l}65.4(13 .) \\
34.6(8.3)\end{array}$ & $\begin{array}{l}36.1 \\
35.2\end{array}$ & $\begin{array}{l}0.001 \\
0.001\end{array}$ & $\begin{array}{l}1.25 \\
1.15\end{array}$ \\
\hline $\begin{array}{r}\text { Early Stance } \\
\text { Terminal Stance }\end{array}$ & $\begin{array}{l}13 \% \\
52 \%\end{array}$ & $\begin{array}{l}98.0(32.5) \\
-41.3(9.9)\end{array}$ & $\begin{array}{c}94.4(32.3) \\
-31.0(13.8)\end{array}$ & $\begin{array}{c}3.7 \\
25.0\end{array}$ & $\begin{array}{l}0.009 \\
0.009\end{array}$ & $\begin{array}{l}0.11 \\
0.86\end{array}$ \\
\hline $\begin{array}{l}\text { Initial Swing } \\
\text { Terminal Swing } \\
\text { Hip Vertical }\end{array}$ & $\begin{array}{l}64 \% \\
88 \%\end{array}$ & $\begin{array}{l}43.8(29.6) \\
-72.8(17.8)\end{array}$ & $\begin{array}{l}73.8(31.8) \\
-90.0(22.9)\end{array}$ & $\begin{array}{l}68.7 \\
23.6\end{array}$ & $\begin{array}{l}<0.001 \\
0.033\end{array}$ & $\begin{array}{l}0.98 \\
0.84\end{array}$ \\
\hline Early Stance & $18 \%$ & $-1042.3(117)$. & $-1002.4(116.9)$ & 3.8 & $<0.001$ & 0.34 \\
\hline $\begin{array}{r}\text { Mid-Stance } \\
\text { Terminal Stance }\end{array}$ & $\begin{array}{l}32 \% \\
47 \%\end{array}$ & $\begin{array}{l}-784.3(95.1) \\
-932.0(108.9)\end{array}$ & $\begin{array}{c}-745.7(95.6) \\
-891.6(109.2)\end{array}$ & $\begin{array}{l}4.9 \\
4.3\end{array}$ & $\begin{array}{l}<0.001 \\
<0.001\end{array}$ & $\begin{array}{l}0.41 \\
0.37\end{array}$ \\
\hline $\begin{array}{r}\text { Initial Swing } \\
\text { Terminal Swing }\end{array}$ & $\begin{array}{l}65 \% \\
95 \%\end{array}$ & $\begin{array}{l}94.5(26.3) \\
53.9(10.2)\end{array}$ & $\begin{array}{c}136.7(23.3) \\
84.0(7.9)\end{array}$ & $\begin{array}{l}44.7 \\
55.9\end{array}$ & $\begin{array}{l}<0.001 \\
<0.001\end{array}$ & $\begin{array}{l}1.70 \\
3.32\end{array}$ \\
\hline \multicolumn{7}{|c|}{ Resultant Joint Moment (Nm) } \\
\hline $\begin{array}{r}\text { Early Stance } \\
\text { Terminal Stance }\end{array}$ & $\begin{array}{l}9 \% \\
50 \%\end{array}$ & $\begin{array}{c}20.0(5.6) \\
-141.5(37.4)\end{array}$ & $\begin{array}{c}20.5(5.6) \\
-140.9(37.3)\end{array}$ & $\begin{array}{l}2.7 \\
0.4\end{array}$ & $\begin{array}{c}0.001 \\
<0.001\end{array}$ & $\begin{array}{l}0.10 \\
0.01\end{array}$ \\
\hline $\begin{array}{r}\text { Mid-Stance } \\
\text { Terminal Stance }\end{array}$ & $\begin{array}{l}21 \% \\
45 \%\end{array}$ & $\begin{array}{l}27.0(31.8) \\
-21.4(21.9)\end{array}$ & $\begin{array}{l}26.1(31.4) \\
-22.3(21.2)\end{array}$ & $\begin{array}{l}3.2 \\
4.5\end{array}$ & $\begin{array}{l}0.053 \\
0.033\end{array}$ & $\begin{array}{l}0.03 \\
0.04\end{array}$ \\
\hline $\begin{array}{r}\text { Initial Swing } \\
\text { Terminal Swing }\end{array}$ & $\begin{array}{l}68 \% \\
96 \%\end{array}$ & $\begin{array}{l}4.4(3.3) \\
-13.7(3 .)\end{array}$ & $\begin{array}{c}8.7(3.4) \\
-28.4(4.9)\end{array}$ & $\begin{array}{c}98.5 \\
108.0\end{array}$ & $\begin{array}{l}0.015 \\
0.001\end{array}$ & $\begin{array}{l}1.26 \\
3.64\end{array}$ \\
\hline $\begin{array}{r}\text { Initial Swing } \\
\text { Terminal Swing }\end{array}$ & $\begin{array}{l}64 \% \\
95 \%\end{array}$ & $\begin{array}{l}20.6(13.0) \\
-19.8(5.2)\end{array}$ & $\begin{array}{l}32.7(11.4) \\
-48.4(9.4)\end{array}$ & $\begin{array}{c}58.8 \\
144.8\end{array}$ & $\begin{array}{c}0.002 \\
<0.001\end{array}$ & $\begin{array}{l}0.99 \\
3.78\end{array}$ \\
\hline
\end{tabular}

Table 2. Peak resultant joint reaction forces and moments averaged across subjects and statistical comparisons between the two inertial models for the prosthetic side's joint kinetics. Notes: Mean data are presented as mean(SD). \% Gait Cycle column represents the average percentage across subjects where the peak value occurred for that variable. $p<.05$ considered significant.

\section{Discussion}

An oscillation and reaction board technique was presented for estimating the inertial properties of below-knee prostheses. This system was validated and shown to be reliable when estimating inertial properties of known geometrical solids (Appendix A). Prosthesis limb inertial properties for a group of unilateral, transtibial amputees were estimated in two ways: a) by direct measurement using oscillation and reaction board techniques, and b) using standard prediction equations created for intact limbs. The resulting inertial property estimates for the prosthetic 
limb were substantially different for two approaches. This difference in inertial properties resulted in significantly different estimates of joint kinetics during walking, with larger differences being observed during swing.

Although significant differences in joint kinetics occurred during stance using the two different inertial parameter estimations, these differences were small when considering the effects sizes for these differences and in comparison with differences observed during swing. In most studies of human movement, these statistically significant differences during stance may not have an impact on the outcomes in the study. Ground reaction forces have a large influence on overall moment magnitudes of lower extremity joints during the stance phase of walking. ${ }^{17-19}$ Even though there were significant differences in the inertial parameters for both models, these differences were not enough to overcome the importance of the ground reaction force contribution to the joint moment production during stance. Miller ${ }^{25}$ also previously suggested that the inertial properties of the prosthetic side had little effect on magnitudes of the lower extremity joint kinetics during the stance phase of running. However, Miller ${ }^{25}$ only took into account the differences in mass and center of mass location of the limb when altering the prosthetic limb's inertial properties for the inverse dynamics model. Differences in moment of inertia were not accounted for in the model, but it was suggested that even if the moment of inertia was doubled or halved it would likely have little effect on the magnitude of the joint moment. The la term in the equation of motion accounted for less than $3 \%$ of the overall joint moment at any given point during the stance phase of running. In absolute terms, the largest change in moment magnitude for our study was observed in the hip joint moment at $\sim 11 \%$ of the gait cycle where the average magnitude increase was $\sim 2 \mathrm{~N} \cdot \mathrm{m}$. This was approximately half of the magnitude increase that was observed by Miller ${ }^{25}$ during the stance phase of running. Our results combined with those of Miller suggest that direct measures of prosthesis inertia, including the moment of inertia, have only a small or negligible effect on the joint moment magnitudes of the hip and knee during the stance phase of walking or running.

With regard to the swing phase of walking, the choice of inertial model does have a significant impact on the magnitudes of lower extremity joint kinetics. During swing, there is no large external force, such as the ground reaction force during stance. The motion of the limb is much more dependent on the inertia in the system and the interactions among the segments. This was reflected by the large changes in joint kinetic magnitudes observed when the two different inertial models were used in the inverse dynamics analysis. Using regression equations based on intact anatomy to model the prosthetic limb during swing, suggested that a greater muscular effort was required than when actual measured inertial properties of the prosthesis were used.

The technique described in this paper to directly measure the inertial properties of a below-knee prosthesis has several limitations. We have described methods and made inertia property measurements of the legs only for sagittal plane analyses. Improvements to this system include creating an inner cage structure that could be suspended from three different axes so that all three principal moments of inertia could be measured. In addition, the reaction board technique could be used for all three planes to measure the three dimensional location of the prosthesis center of mass. Another improvement that could make the estimates of the residual limb mass slightly more accurate would be to use a volumetric assessment as described by Czerniecki and colleagues ${ }^{24}$ where the residual limb is suspended in a cylinder of water to estimate its volume while a uniform tissue density is applied to estimate the limb's mass. Additionally, instead of using an assumed percentage to distribute the total prosthesis mass between the prosthetic socket and foot, each prosthesis could be disarticulated at the ankle so that each component could be weighed independently. Another limitation of our technique is that it does require some additional time during an experimental session. In general, using our technique to directly measure the prosthesis inertia will likely add 30 min to the total time needed for a data collection session.

Because of our small sample of below-knee prostheses with similar designs (i.e., lock and pin suspensions and dynamic elastic response prosthetic feet), developing definitive recommendations for estimating inertial properties of below knee prosthetic limbs as simple percentages of intact limb inertia properties is problematic. Nevertheless, combining our results with inertial estimates for below-knee prostheses from other studies $^{20,21,23}$ and comparing these outcomes to inertia estimates for intact limbs, some consistent trends become apparent. Compared to the intact limb, the mass of the prosthetic side is consistently $30-40 \%$ less, the COM location is $25-35 \%$ closer to the knee joint, and the MOI is $50-60 \%$ less about a transverse axis through the knee joint.

In conclusion, using regression equations for an intact shank and foot to model the inertial properties of a below-knee prosthesis will impact the magnitudes of joint kinetic estimates during swing, but will have only a small or minimal impact on these magnitudes during stance. Thus, for researchers focusing only on the stance phase of locomotion using inertial properties of the intact limb to model the prosthetic side will not likely alter conclusions of the study. However, for those interested in swing phase kinetics, direct measures of the prosthesis inertial properties should be considered to avoid misrepresenting the true dynamics of prosthetic leg swing.

\section{Appendix A}

\section{Reliability and Validity of Moment of Inertia and Center of Mass Estimations}

To assess reliability and validity of our experimental measurements of prosthesis moment of inertia and center of mass location, two simple experiments were performed. In the first experiment, moments of inertia and center of mass locations of four objects were experimentally estimated in three separate trials. The four objects were: 1) $9 \times 9 \times 61 \mathrm{~cm}$ block of treated lumber (mass $=2.8 \mathrm{~kg}$ ), 2$) 9 \times 9 \times 64 \mathrm{~cm}$ block of untreated lumber (mass = 2.5 kg), 3) $7 \times 9 \times 65 \mathrm{~cm}$ block of untreated lumber (mass = 1.8 kg), and 4) $61 \mathrm{~cm}$ long piece of PVC pipe with and inside diameter of $8 \mathrm{~cm}$ and an outside diameter of $9 \mathrm{~cm}$ (mass $=0.8 \mathrm{~kg}$ ). An oscillation technique ${ }^{12}$ was used to estimate each object's moment of inertia about a transverse axis through its center mass. When an object oscillates about a fixed axis, the period of oscillation ( $\mathrm{T}$ ) of the object is proportional to the object's moment of inertia about that fixed axis. If the oscillation amplitude is less than $5^{\circ}$ relative to a neutral position, the moment of inertia of the object can be estimated based on the motion of a simple pendulum:

$\tau=2 \pi \sqrt{\frac{I_{a x i s}}{m g d}}($ A.1) 
where $\mathrm{I}_{\text {axis }}$ is the moment of inertia relative to the oscillation axis, $\mathrm{m}$ is the mass of the system, $\mathrm{g}$ is the acceleration due to gravity, and $\mathrm{d}$ is the distance between the oscillation axis and the center of mass of the system.

A reaction board technique was used to estimate each object's center of mass location. Static equilibrium was assumed $\left(\Sigma_{\text {Moments }}=0\right)$ and the moments produced by the weight of the object, weight of the frame, and reaction force were summed about a fixed reference axis. The moment of inertia and center of mass location of each object were also estimated based on simple geometric equations. Our experimental measures were compared to these geometric estimations to assess validity. Reliability of our estimates for center of mass location and moment of inertia was assessed using two (one for COM estimation and one for MOI estimation), single factor general linear model ANOVAs, with 3 repeated measures reflecting the three trials. Intraclass correlation coefficients (ICCs) were also computed to determine the repeatability of our estimations.

In a second experiment, we assessed the reliability of our period of oscillation $(\mathrm{T})$ measurement. $\mathrm{T}$ was measured for 10 consecutive trials with only the aluminum frame suspended from the oscillation axis and 10 consecutive trials with a wooden block $($ mass $=2.8 \mathrm{~kg}$, dimensions $=9 \mathrm{x}$ $9 \times 61 \mathrm{~cm}$ ) secured in the aluminum frame and both suspended from the oscillation axis. During each trial, T was measured for 10 consecutive oscillations using a photocell whose output voltage varied based on the reflected light intensity. Reliability of our measurement for $\mathrm{T}$ was assessed using four, single factor general linear model ANOVAs, with 10 repeated measures. Two (one for frame only trials and one for frame + block trials) ANOVAs were used to determine whether t differed between consecutive oscillations (i.e., the data matrix was setup so that the factor was consecutive periods of oscillation within a given trial). Then the data matrices were rotated by $90^{\circ}$ so that the factor was consecutive trials and two more ANOVAs were used to determine whether t differed across consecutive trials. Intraclass correlation coefficients (ICCs) were also computed to determine the repeatability of our measurements.

\section{Results of Experiment 1 - The Four Objects}

Each object's moment of inertia about a transverse axis through its center of mass (I_obj_cm) was consistently overestimated (by $\sim 5 \%$ for wooden blocks and by $\sim 12 \%$ for PVC pipe) compared to the estimations based on each object's mass and geometry (Iz) (Table 3). Our estimations, however, were extremely reliable. There was no difference in the mean moment of inertia $\left(F_{2,6}=0.154 ; p=0.861\right)$ for the four objects across the three trials. In addition, ICCs revealed that across trials our moment of inertia estimation was highly repeatable $($ ICC $=1.00)$. Thus, although our estimation tended to overestimate the object's moment of inertia compared to the geometric estimate our estimations were reliable.

Our center of mass location estimation using a reaction board technique was consistent with estimations based on assuming uniform density and a geometric model. Differences were less than $1 \%$. There was no difference in the mean center of mass location $\left(F_{2,6}=1.126 ; p=0.384\right)$ for the four objects across the three trials. In addition, ICCs revealed that across trials our center of mass estimation was highly repeatable (ICC $>0.99)$. Thus, our center of mass estimations were valid and reliable.

\begin{tabular}{|c|c|c|c|c|c|c|c|c|c|c|c|c|}
\hline & \multicolumn{3}{|c|}{$61 \mathrm{~cm}$ long PVC Pipe } & \multicolumn{3}{|c|}{$9 \times 9 \times 61 \mathrm{~cm}$ block of Wood } & \multicolumn{3}{|c|}{$9 \times 9 \times 64 \mathrm{~cm}$ block of Wood } & \multicolumn{3}{|c|}{$7 \times 9 \times 61 \mathrm{~cm}$ block of Wood } \\
\hline & Trial 1 & Trial 2 & Trial 3 & Trial 1 & Trial 2 & Trial 3 & Trial 1 & Trial 2 & Trial 3 & Trial 1 & Trial 2 & Trial 3 \\
\hline mframe (g) & 1842.00 & 1842.67 & 1843.00 & 1842.33 & 1842.33 & 1842.67 & 1842.67 & 1843.00 & 1843.67 & 1842.67 & 1843.00 & 1843.33 \\
\hline mobject (g) & 833.67 & 833.67 & 833.00 & 2798.00 & 2797.00 & 2796.33 & 2461.67 & 2455.00 & 2452.67 & 716.67 & 716.00 & 716.33 \\
\hline t_frame (s) & 1.5622 & 1.5619 & 1.5628 & 1.5631 & 1.5628 & 1.5626 & 1.5676 & 1.5686 & 1.5689 & 1.5726 & 1.5731 & 1.5738 \\
\hline t_object (s) & 1.5313 & 1.5314 & 1.5319 & 1.5020 & 1.5025 & 1.5020 & 1.5024 & 1.5026 & 1.5028 & 1.5360 & 1.5357 & 1.5366 \\
\hline I_Frame_osc (kg-m-m) & 0.4052 & 0.4043 & 0.4055 & 0.4038 & 0.4045 & 0.4047 & 0.4011 & 0.4015 & 0.4020 & 0.3981 & 0.3983 & 0.3988 \\
\hline I_Frame_obj_osc (kg-m-m) & 0.6158 & 0.6153 & 0.6153 & 1.1031 & 1.1048 & 1.1043 & 0.9920 & 0.9895 & 0.9894 & 0.5662 & 0.5660 & 0.5667 \\
\hline I_obj_osc (kg-m-m) & 0.2106 & 0.2110 & 0.2098 & 0.6993 & 0.7003 & 0.6997 & 0.5908 & 0.5880 & 0.5873 & 0.1681 & 0.1678 & 0.1679 \\
\hline I_obj_cm (kg-m-m) & 0.0294 & 0.0296 & 0.0300 & 0.0916 & 0.0933 & 0.0925 & 0.0890 & 0.0887 & 0.0889 & 0.0270 & 0.0264 & 0.0268 \\
\hline $\mathrm{Iz}(\mathrm{kg}-\mathrm{m}-\mathrm{m})$ & 0.0266 & 0.0266 & 0.0265 & 0.0886 & 0.0886 & 0.0886 & 0.0842 & 0.0840 & 0.0839 & 0.0256 & 0.0256 & 0.0256 \\
\hline I_obj_cm and Iz difference (\%) & 10.5475 & 11.4266 & 12.9746 & 3.3391 & 5.3468 & 4.4983 & 5.6311 & 5.6542 & 5.9372 & 5.5197 & 3.1809 & 4.7917 \\
\hline Measured CM Location (m) & 0.3067 & 0.3071 & 0.3049 & 0.3073 & 0.3071 & 0.3073 & 0.3170 & 0.3167 & 0.3166 & 0.3258 & 0.3271 & 0.3263 \\
\hline Geometric CM Location (m) & 0.3050 & 0.3050 & 0.3050 & 0.3050 & 0.3050 & 0.3050 & 0.3175 & 0.3175 & 0.3175 & 0.3255 & 0.3255 & 0.3255 \\
\hline Geom. and Meas. CM diff. (\%) & 0.5415 & 0.6873 & -0.0318 & 0.7408 & 0.6811 & 0.7621 & -0.1670 & -0.2452 & -0.2750 & 0.1020 & 0.4801 & 0.2531 \\
\hline
\end{tabular}

Table 3. Our experimental estimations of moments of inertia and center of mass locations for the four objects compared to estimations based on the mass and geometry of each object. Click here to get an enlarged view of the table. Variable definitions: mframe $=$ mass of the aluminum frame; mobject = mass of the object; $t$ frame = period of oscillation of the frame only; period of oscillation was determined as the mean of 10 consecutive oscillations and across three consecutive trials. $t$ _object $=$ period of oscillation of frame and object together; determined the same as $t$ frame; I_Frame_osc = I of the frame relative to the oscillation axis; I_Frame_obj_osc = I of the frame plus object relative to the oscillation axis; I_obj_osc = I of the object relative to the oscillation axis; I_obj_cm = I of the object about an axis through the object's center of mass; $\mathrm{Iz}=$ Theoretical prediction of I about the object's CM using the following geometric prediction equations:

PVC: $\mathrm{Iz}=\frac{\text { mobject }}{12} *\left(3 \mathrm{R}^{2}+3 \mathrm{r}^{2}+\mathrm{h}^{2}\right) ;$ where $\mathrm{R}$ was outer radius, $\mathrm{r}$ was inner radius, and $\mathrm{h}$ was length

Wood: $\mathrm{Iz}=\frac{\text { mobject }}{12} *\left(\mathrm{a}^{2}+\mathrm{b}^{2}\right)$; where $\mathrm{a}$ is length and $\mathrm{b}$ is width Geometric CM location was predicted as $50 \%$ of the object length.

\section{Results of Experiment 2 - Period of Oscillation (т) Assessment}

When the aluminum frame alone was suspended from the oscillation axis and swung, $\mathrm{T}$ consistently and systematically decreased $\left(\mathrm{F}_{9,81}=\right.$ 123.25; $p<0.001$ ) over the first 10 oscillations by approximately $6 \mathrm{msec}$ in all 10 oscillation trials (Figure 5 ; left panel). Across trials, the mean period of oscillation was also found to differ significantly $\left(F_{9,81}=13.97 ; p<0.001\right)$ when only the frame was oscillated. However, ICCs revealed 
that within a given trial the systematic decrease in $\mathrm{T}$ over the first 10 oscillations was repeatable $($ ICC $=0.99)$. When the frame and wooden block $\left(m=2797 \mathrm{~g}\right.$ ) were swung together, $\mathrm{T}$ did not change over the first 10 oscillations $\left(F_{9,81}=3.031 ; p=0.116\right)$ and the mean $\mathrm{T}$ across 10 consecutive trials did not significantly differ $\left(F_{9,81}=3.533 ; p=0.093\right)$ (Figure 5; right panel). ICCs for the frame plus object trials suggest that within a given trial $\mathrm{T}$ is not repeatable from oscillation to oscillation $(I C C=0.17)$. These data suggest that for the frame only trials $\mathrm{T}$ is better estimated as a mean of the first oscillation across a series of trials and that when an object with characteristics similar to those of a below-knee prosthesis is oscillated, $\mathrm{T}$ is better estimated as the mean across consecutive oscillations and across a number of trials.
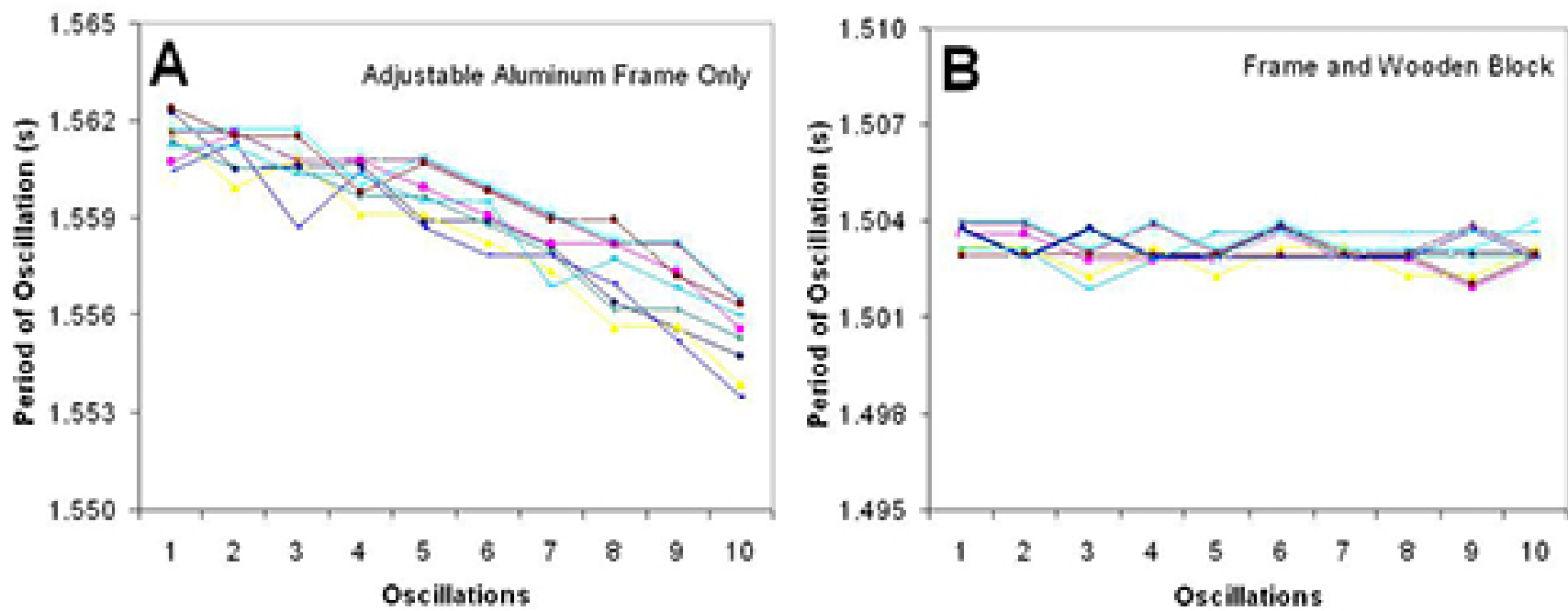

Figure 5. Period of oscillation measured for (A) aluminum frame only and (B) frame and wooden block (block mass $=2.8 \mathrm{~kg}$, block dimensions $=9 \times 9 \times 61 \mathrm{~cm})$. Each panel shows 10 separate trials with the first 10 oscillations of each trial displayed. With only the frame suspended from the oscillation axis (left panel), t systematically decreased over the first 10 oscillations. However, when a wooden block was added to the frame, $\mathrm{T}$ did not systematically vary across the first 10 oscillations (right panel).

\section{Sensitivity of Moment of Inertia to Period of Oscillation}

Because results from experiment 1 suggest our estimations of an object's moment of inertia are consistently overestimated and results from experiment 2 suggest that $\mathrm{T}$ of the frame decreases over the first 10 oscillations, we performed a sensitivity analysis to determine the best method for quantifying $\mathrm{T}$ for frame only trials and frame plus object trials (Table 4). $\mathrm{T}$ is directly proportional to the moment of inertia of an object:

$\tau=2 \pi \sqrt{\frac{I_{a x i s}}{m g d}}($ A.2)

where $\mathrm{I}_{\text {axis }}$ is the moment of inertia relative to the oscillation axis, $\mathrm{m}$ is the mass of the system, $\mathrm{g}$ is the acceleration due to gravity, and $\mathrm{d}$ is the distance between the oscillation axis and the center of mass of the system. Therefore, if $\mathrm{T}$ decreases, then so does $\mathrm{l}_{\mathrm{axis}}$ because $\mathrm{m}$, $\mathrm{g}$, and $\mathrm{d}$ are constants within a given trial. Since we estimate the moment of inertia of an object as:

$I_{o b j}=I_{o b j+f r a m e}-I_{\text {rame }}(A .3)$

underestimating the moment of inertia of the frame $\left(\mathrm{I}_{\text {frame }}\right)$ will produce a larger moment of inertia estimate for the object $\left(\mathrm{I}_{\text {obj }}\right)$, which is consistent with our estimations in experiment 1. Figure 6 displays t from experiment 1 for both the frame only trials and frame plus object trials for the lightest object and heaviest object. This figure illustrates that for heavier objects (e.g., below knee prosthesis) there is no evident decrease in $\mathrm{T}$ over the first 10 oscillations, but for lighter objects there is a slight systematic decrease in $\mathrm{T}$. 


\begin{tabular}{|c|c|c|c|c|c|c|c|c|c|c|c|c|}
\hline & \multicolumn{3}{|c|}{ Condition A } & \multicolumn{3}{|c|}{ Condition B } & \multicolumn{3}{|c|}{ Condition C } & \multicolumn{3}{|c|}{ Condition D } \\
\hline & Test 1 & Test 2 & Test 3 & Test 1 & Test 2 & Test 3 & Test 1 & Test 2 & Test 3 & Trial 1 & Trial 2 & Trial 3 \\
\hline mframe (g) & 1842.33 & 1842.33 & 1842.67 & 1842.33 & 1842.33 & 1842.67 & 1842.33 & 1842.33 & 1842.67 & 1842.33 & 1842.33 & 1842.67 \\
\hline mobject $(g)$ & 2798.00 & 2797.00 & 2796.33 & 2798.00 & 2797.00 & 2796.33 & 2798.00 & 2797.00 & 2796.33 & 2798.00 & 2797.00 & 2796.33 \\
\hline t_frame (s) & 1.5631 & 1.5628 & 1.5626 & 1.5644 & 1.5646 & 1.5643 & 1.5644 & 1.5646 & 1.5643 & 1.5631 & 1.5628 & 1.5626 \\
\hline t_object (s) & 1.5020 & 1.5025 & 1.5020 & 1.5024 & 1.5030 & 1.5027 & 1.5020 & 1.5025 & 1.5020 & 1.5024 & 1.5030 & 1.5027 \\
\hline I_Frame_osc (kg-m-m) & 0.4038 & 0.4045 & 0.4047 & 0.4045 & 0.4050 & 0.4051 & 0.4045 & 0.4050 & 0.4051 & 0.4038 & 0.4041 & 0.4043 \\
\hline I_Frame_obj_osc $(\mathrm{kg}-\mathrm{m}-\mathrm{m})$ & 1.1031 & 1.1048 & 1.1043 & 1.1038 & 1.1044 & 1.1043 & 1.1031 & 1.1037 & 1.1032 & 1.1038 & 1.1044 & 1.1043 \\
\hline I_obj_osc $(\mathrm{kg}-\mathrm{m}-\mathrm{m})$ & 0.6993 & 0.7003 & 0.6997 & 0.6993 & 0.6993 & 0.6991 & 0.6987 & 0.6987 & 0.6981 & 0.7000 & 0.7003 & 0.7000 \\
\hline I_obj_cm (kg-m-m) & 0.0916 & 0.0933 & 0.0925 & 0.0915 & 0.0923 & 0.0920 & 0.0909 & 0.0916 & 0.0910 & 0.0922 & 0.0932 & 0.0929 \\
\hline $\mathrm{Iz}(\mathrm{kg}-\mathrm{m}-\mathrm{m})$ & 0.0886 & 0.0886 & 0.0886 & 0.0886 & 0.0886 & 0.0886 & 0.0886 & 0.0886 & 0.0886 & 0.0886 & 0.0886 & 0.0886 \\
\hline I_obj_cm and $\mathrm{Iz}$ differe $n \propto(\%)$ & 3.3391 & 5.3468 & 4.4983 & 3.2951 & 4.2086 & 3.8946 & 2.5910 & 3.4726 & 2.7109 & 4.0432 & 5.2768 & 4.8765 \\
\hline
\end{tabular}

Table 4. Comparison of four different methods for determining period of oscillation. The object used in this analysis was the $9 \times 9 \times 61 \mathrm{~cm}$ block of treated lumber. Condition $\mathrm{C}$ produced the best estimate of the object's moment of inertia when compared to an alternative theoretical estimation based on the object's mass and geometry. Click here to get an enlarged view of the table. Notes: Variable definitions are the same as Table 3. Condition A: $t$ _frame and t_object were computed as the mean period of oscillation of 10 consecutive oscillations across 3 trials. Condition B: $t$ frame and $t$ _object were computed as the mean of the first period of oscillation across 3 separate trials. Condition C: $t$ frame was determined as in Condition B; t_object was determined as in Condition A. Condition D: t_frame was determined as in Condition A; t_object was determined as in Condition B.
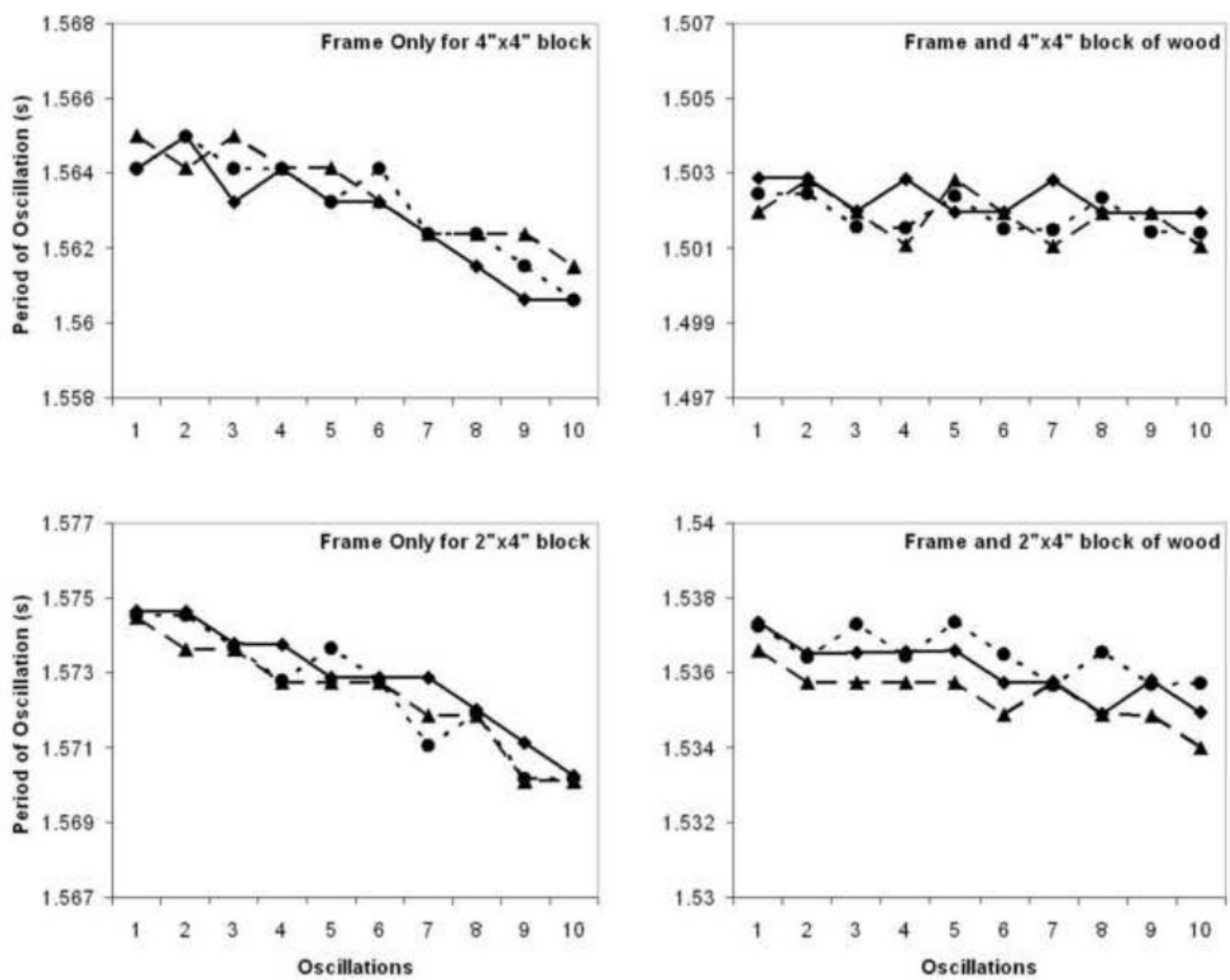

Figure 6. Periods of oscillation for the heaviest and lightest objects. The left panels display the first 10 periods of oscillation of three trials for the frame only, and the right panels display the same for the frame plus object trials. As in experiment 2, there is a systematic decrease in T over the first 10 oscillations when only the frame is oscillated. When the heavy object was oscillated $(\mathrm{m}=2.797 \mathrm{~kg})$, there was no systematic decrease in $\mathrm{T}$. However, a slight decrease in t was observed when the light object $(\mathrm{m}=0.716 \mathrm{~kg})$ was oscillated. Typical below-knee prosthesis mass has been reported to range from 1.2 to $2.1 \mathrm{~kg}^{20,21}$. Thus, even for the lightest weight prostheses, $\mathrm{T}$ should not exhibit a substantial decrease over the first 10 oscillations.

\section{Conclusion}

When the aluminum frame alone is oscillated, the period of oscillation will be determined as the mean of the first oscillation from 10 oscillation trials. When the aluminum frame and prosthesis are oscillated, the period of oscillation will be determined as the mean of 30 oscillations ( 3 trials, 10 consecutive oscillations within each trial). 


\section{Disclosures}

The authors declare that they have no competing financial interests.

\section{Acknowledgements}

Funding from the American and International Societies of Biomechanics was provided for this study.

\section{References}

1. Chandler, R. F., Clauser, C.E., McConville, J.T., Reynolds, H.M., and Young, S.W. Investigation of the inertial properties of the human body. Pamphlets DOT HS-801 430 and AMRL TR-74-137. Wright Patterson Air Force Base, OH (1975).

2. Clauser, C. E., McConville, J. T., \& Young, J. W. Weight, Volume, and Center of Mass of Segments of the Human Body. AMRL Technical Report. Wright-Patterson Air Force Base, OH, 60-70 (1969).

3. Dempster, W. Space requirements of the seated operator. WADC Technical Report. Wright Patterson Air Force Base, OH, 55-159 (1955).

4. Hinrichs, R. N. Regression equations to predict segmental moments of inertia from anthropometric measurements: an extension of the data of Chandler et al. (1975). J Biomech. 18, 621-624, doi:0021-9290(85)90016-8 [pii] (1985).

5. Hinrichs, R. N. Adjustments to the segment center of mass proportions of Clauser et al. (1969). J Biomech. 23, 949-951, doi:0021-9290(90)90361-6 [pii] (1990).

6. Hanavan Jr., E. P. A mathematical model of the human body. Amrl-Tr-64-102. AMRL Technical Report. Wright-Patterson Air Force Base, OH. 18, 1-149 (1964).

7. Hatze, H. A mathematical model for the computational determination of parameter values of anthropomorphic segments. J Biomech. 13, 833-843, doi:0021-9290(80)90171-2 [pii] (1980).

8. Leva, P. Adjustments to Zatsiorsky-Seluyanov's segment inertia parameters. J Biomech. 29, 1223-1230 (1996).

9. Durkin, J. L., \& Dowling, J. J. Analysis of body segment parameter differences between four human populations and the estimation errors of four popular mathematical models. J Biomech Eng. 125, 515-522 (2003).

10. Durkin, J. L., Dowling, J. J., \& Andrews, D. M. The measurement of body segment inertial parameters using dual energy X-ray absorptiometry. J Biomech. 35, 1575-1580, doi:S0021929002002270 [pii] (2002).

11. Jensen, R. K. Estimation of the biomechanical properties of three body types using a photogrammetric method. J Biomech. 11, 349-358, doi:0021-9290(78)90069-6 [pii] (1978).

12. Martin, P. E., Mungiole, M., Marzke, M. W., \& Longhill, J. M. The use of magnetic resonance imaging for measuring segment inertial properties. J Biomech. 22, 367-376 (1989).

13. Mungiole, M., \& Martin, P. E. Estimating segment inertial properties: comparison of magnetic resonance imaging with existing methods. $J$ Biomech. 23, 1039-1046 (1990).

14. Zatsiorsky, V. M., \& Seluyanov, V. N. The mass and inertia characteristics of the main segments of the human body. Biomechanics VIII-B. 1152-1159 (1983).

15. Zatsiorsky, V. M., \& Seluyanov, V. N. in Biomechanics IX-B. (ed D. A. Winter, Norman, R., Wells, R. P., Hayes, K. C., and Patla, A. E.) 233-239. Human Kinetics, (1985).

16. Challis, J. H. Precision of the Estimation of Human Limb Inertial Parameters. Journal of Applied Biomechanics. 15, 418-428 (1999).

17. Challis, J. H. Accuracy of Human Limb Moment of Inertia Estimations and Their Influence on Resultant Joint Moments. Journal of Applied Biomechanics. 12, 517-530 (1996).

18. Challis, J. H., \& Kerwin, D. G. Quantification of the uncertainties in resultant joint moments computed in a dynamic activity. J Sports Sci. 14, 219-231 (1996).

19. Hunter, J. P., Marshall, R. N., \& McNair, P. J. Segment-interaction analysis of the stance limb in sprint running. J Biomech. 37, 1439-1446 (2004).

20. Lin-Chan, S. J. et al. The effects of added prosthetic mass on physiologic responses and stride frequency during multiple speeds of walking in persons with transtibial amputation. Arch Phys Med Rehabil. 84, 1865-1871 (2003).

21. Mattes, S. J., Martin, P. E., \& Royer, T. D. Walking symmetry and energy cost in persons with unilateral transtibial amputations: matching prosthetic and intact limb inertial properties. Arch Phys Med Rehabil. 81, 561-568. (2000).

22. Smith, J. D., \& Martin, P. E. Short and longer term changes in amputee walking patterns due to increased prosthesis inertia. $J$ Prosthet Orthot. 23, 114-123 (2011).

23. Smith, J. D., \& Martin, P. E. Effects of prosthetic mass distribution on metabolic costs and walking symmetry. J Appl Biomech. 29, 317-328 (2013).

24. Czerniecki, J. M., Gitter, A., \& Munro, C. Joint moment and muscle power output characteristics of below knee amputees during running: the influence of energy storing prosthetic feet. J Biomech. 24, 63-75 (1991).

25. Miller, D. I. Resultant lower extremity joint moments in below-knee amputees during running stance. J Biomech. 20, 529-541 (1987).

26. Vanicek, N., Strike, S., McNaughton, L., \& Polman, R. Gait patterns in transtibial amputee fallers vs. non-fallers: Biomechanical differences during level walking. Gait \& Posture. 29, 415-420, doi:http://dx.doi.org/10.1016/j.gaitpost.2008.10.062 (2009).

27. Royer, T., \& Koenig, M. Joint loading and bone mineral density in persons with unilateral, trans-tibial amputation. Clin Biomech (Bristol, Avon). 20, 1119-1125 (2005)

28. Underwood, H. A., Tokuno, C. D., \& Eng, J. J. A comparison of two prosthetic feet on the multi-joint and multi-plane kinetic gait compensations in individuals with a unilateral trans-tibial amputation. Clin Biomech (Bristol, Avon). 19, 609-616 (2004).

29. Sjodahl, C., Jarnlo, G. B., Soderberg, B., \& Persson, B. M. Kinematic and kinetic gait analysis in the sagittal plane of trans-femoral amputees before and after special gait re-education. Prosthet Orthot Int. 26, 101-112 (2002).

30. Bateni, H., \& Olney, S. Kinematic and kinetic variations of below-knee amputee gait. Journal of Prosthetics and Orthotics. 14, 2-12 (2002). 
31. Buckley, J. G. Biomechanical adaptations of transtibial amputee sprinting in athletes using dedicated prostheses. Clin Biomech (Bristol, Avon). 15, 352-358 (2000).

32. Yack, H. J., Nielsen, D. H., \& Shurr, D. G. Kinetic patterns during stair ascent in patients with transtibial amputations using three different prostheses. Journal of Prosthetics and Orthotics. 11, 57-62 (1999). 